\title{
False memory in nonhuman animals
}

\author{
Paula M. Millin ${ }^{1}$ and David C. Riccio ${ }^{2}$ \\ ${ }^{7}$ Department of Psychology, Kenyon College, Gambier, Ohio 43022, USA; ${ }^{2}$ Department of Psychology, Kent State University, \\ Kent, Ohio 44242, USA
}

\begin{abstract}
This paper examines recent evidence from behavioral and neuroscience research with nonhuman animals that suggests the intriguing possibility that they, like their human counterparts, are vulnerable to creating false memories. Once considered a uniquely human memory phenomenon, the creation of false memories in lower animals can be seen especially readily in studies involving memory for source, or contextual attributes. Furthermore, evidence of "implanted" misinformation has also been obtained. Here, we review that research and consider its relevance to our empirical understanding of false memories, as well as speculate about its potential clinical implications for trauma memory.
\end{abstract}

The creation of false memories in human beings is a topic that has generated much empirical work (for reviews, see Zaragoza et al. 2007; Laney and Loftus 2013) as well as public interest (a simple Google search produces hundreds of news stories from popular culture news outlets). It has been the subject of vigorous debate among researchers owing to its profound legal and clinical implications (for review, see Loftus 1997a). Experts in the field have even disagreed about how to define false memory, with some supporting a broad definition that includes distortion of existing memories due to a failure of source monitoring or to the introduction of misinformation, while others feel strongly that the term should be reserved to describe situations in which a person has come to believe that they remember an entire event that never happened (for an excellent review of this debate, see Wade et al. 2007). According to Wade et al. (2007), a review of the false memory literature suggests that the more inclusive conceptualization better reflects the tenor of the field of over the past two decades. Here, we propose that there is ample evidence of (something akin to) false memory in nonhuman animals, provided that false memory is broadly defined. Just as infantile amnesia, which was long considered a uniquely human phenomenon, has been shown in research with animals to be a fundamental psychobiological outcome (Campbell and Campbell 1962), we believe that false memory is the result of basic memory processes present in lower animals. Moreover, we consider the relevance of false memory in nonhuman animals to the ongoing debates in the human false memory literature and speculate about potential clinical implications.

\section{A case for episodic memory in nonhuman animals: a necessary condition for false memory}

For many decades psychologists and neuroscientists assumed that lower animals lacked the capacity for episodic memory, which is the conscious recollection of personally experienced events, including "what, where, and when" details and requiring the capacities of "self-concept, autonoetic awareness/consciousness, and the ability to subjectively sense time" (Dere et al. 2006). While it is admittedly difficult-perhaps impossible-to produce evidence of autonoetic consciousness or self-awareness in nonhuman animals (one cannot ask a rat if it remembers personally experiencing a particular episode) we might be wise to follow the advice of Basile (2015) who noted that while "we cannot test the subjective feeling

\section{Corresponding author: millinp@kenyon.edu}

Article is online at http://www.learnmem.org/cgi/doi/10.1101//m.050054.119. of pastness in honhuman animals ... we must identify similarities and differences by focusing on those characteristics of episodic memory that are objectively testable." In that regard, he argues, "we have made great progress" (Basile 2015, p. 2). We agree. In recent years, a convergence of behavioral and neurophysiological evidence suggests that lower animals do indeed create episodic memories (for review, see Dere et al. 2006) and that the hippocampus is critically involved in episodic recollection (Fortin et al. 2004). Although a detailed description of myriad studies supporting such a view is beyond the scope of this paper, several brief examples are illustrative and importantly lay the groundwork for the possibility that nonhuman animals create false memories, which are certainly episodic in nature.

An early study with Scrub Jays provided evidence of nonhuman animals' ability to remember "what, when, and where" (Clayton and Dickinson 1999). In their study, Clayton and Dickinson (1999) reported that Scrub Jays could accurately locate worms and nuts that they had hidden previously. As worms were their preferred food, they were located and consumed first when the retention interval was relatively short. However, with longer intervals, and having learned that worms deteriorate over time (and were acceptable but now less preferred), the Jays chose to retrieve the nuts before the worms.

In a more recent study with rats, Babb and Crystal (2005) were able to show that with extensive training, rats formed a what, where, and when memory for the location of a highly preferred food reward (a chocolate-flavored pellet) in a radial maze. In that study, rats received a single "forced choice" sample trial and a single test trial per day. During the daily sample trial, four randomly chosen arms of an eight-arm radial maze were open and one of those arms was baited with a chocolate pellet while the other three were baited with a standard food pellet (nonbaited arms were closed). During the subsequent "free-choice" test trial, which occurred either $30 \mathrm{~min}$ or $4 \mathrm{~h}$ after the training trial, all eight arms were open. On days when the training-to-test delay interval was $30 \mathrm{~min}$, only the four previously closed (nonbaited) arms provided food (standard pellets). On days when the delay interval was $4 \mathrm{~h}$, in addition to standard pellets being available in the four previously unbaited arms, a chocolate pellet was available in the same arm

2019 Millin and Riccio This article is distributed exclusively by Cold Spring Harbor Laboratory Press for the first 12 months after the full-issue publication date (see http://learnmem.cshlp.org/site/misc/terms.xhtml). After 12 months, it is available under a Creative Commons License (AttributionNonCommercial 4.0 International), as described at http://creativecommons. org/licenses/by-nc/4.0/. 
that had been baited with the chocolate reward during that day's forced-choice trial. Results showed that the rats visited the chocolate arm significantly more frequently when tested after a long retention interval than after a short interval. In a second phase of the experiment, the incentive value of the chocolate reward was degraded by pairing it with $\mathrm{LiCl}$ in a taste-aversion paradigm. Following taste aversion conditioning, rats significantly reduced revisits to the chocolate location during long-delay tests. According to Babb and Crystal (2005), "Because chocolate revisits declined after $\mathrm{LiCl}$ treatment, in conditions that controlled the level of relative familiarity, knowledge of what, when, and where is a single parsimonious interpretation for the selective revisits to chocolate before $\mathrm{LiCl} \ldots$ and the decline in visits to chocolate after LiCl." That rats were able to apply new information (chocolate leads to illness) to an old memory (what, where, and when chocolate is available) to modify their ongoing behavior (stop visiting the chocolate arm after taste aversion training) suggests that they were able to use their memories flexibly, a hallmark of episodic memory in humans.

In order to determine if pigeons were capable of something like episodic memory and to avoid the potential problem of rule learning, Zentall et al. (2001) used a strategy in which birds were "asked" if they knew what response they had just made. In the first of two experiments, birds were initially trained on a discrimination task that involved them responding to one color after making a peck and to a different color after not pecking, as a way of indicating what they had done. Subsequently, the pigeons received discriminated autoshaping, a form of Pavlovian conditioning. Presentation of one stimulus (e.g., vertical line) was followed by food and a different stimulus (horizontal line) by no food. In this preparation pigeons typically come to peck at the vertical line even though no response contingency is in effect. Once the differential performance was established, a test was introduced in which the two color stimuli were presented after pigeons had either been pecking or not. By choosing the correct color the birds indicated with a reasonable degree of accuracy what they had done last.

A second experiment took advantage of the finding that pigeons tend to peck at a lighted key but not at a dark one, so no training was involved to establish the behavior of interest. After one or the other of the types of key presentations, the birds were "queried" about their last behavior, and their correct choice of color stimuli indicated accurate recall of whether or not they had pecked (Zentall et al. 2001). These and similar demonstrations of episodic memory in lower animals are important since false memories occur in relation to episodic memories.

\section{False memory takes various forms}

\section{Source confusion, stimulus generalization, and context forgetting}

An important and common form of false memory in humans is source confusion, whereby the target information, but not the source from which it came, is correctly recalled (see Mitchell and Johnson 2009 for an extensive review of the literature, including the likely brain mechanisms involved; for an analysis of the variables contributing to source confusion within a source monitoring framework, see Johnson et al. 1993). An everyday example is recalling a news item but incorrectly recalling that it came from the newspaper, when, in fact, you read about it on the internet. A classic empirical example is provided by a study in which college students were presented with a series of facial photographs in one of two different rooms. When tested $2 \mathrm{~d}$ later, students showed highly accurate recognition for the faces but poor recall for the source, that is, the room (Brown et al. 1977). Similarly, in a study by Schacter et al. (1984), one of two women presented information to college student participants. Conditional on recalling the target information, students were asked to identify which of the women was the correct source. Source confusion was common in that study, and was contrasted with that of amnesia patients, who often attributed the information to an external source such as a TV program or newspaper report, an outcome Schacter labeled source amnesia.

Early evidence of source confusion can be seen in the experimental work on stimulus generalization in both human and nonhuman animals. Stimulus generalization is the tendency to respond to stimuli similar, but not identical, to stimuli that predict an event or outcome. A very famous example from the human conditioning literature is provided by Watson and Rayner's subject, Little Albert, who demonstrated generalized fear to objects such as a white rabbit and a Santa Claus mask after aversive conditioning with a white rat (Watson and Rayner 1920). An early example with pigeons demonstrated that following reinforcement for pecking a $580 \mathrm{~nm}$ lighted disk, pigeons also pecked 570 and $590 \mathrm{~nm}$ wavelengths with high frequency (Guttman and Kalish 1956). While the basic phenomenon of stimulus generalization is widely acknowledged, the finding that generalization tends to increase as a function of the training to testing interval is less well known. This "flattening of the generalization gradient," was first reported by Perkins and Weyant (1958) and was investigated further in an operant conditioning paradigm by Thomas and Lopez (1962) and Thomas and Burr (1969). Their findings demonstrated a loss of precision of memory for the specific cues associated with an event, resulting in an increase in "false positives" over time. Those false positives, or the tendency to increasingly respond to nonreinforced stimuli as though they were the trained stimulus, bear a striking resemblance to other misattribution errors, such as source confusion, which also increase as the delay between learning and recall increases (Schacter et al. 1984).

A related phenomenon frequently reported in the animal literature and more directly analogous to source confusion is the impairment of memory accuracy for contextual cues, which has likewise been shown to increase over a retention interval (McAllister and McAllister 1963; Gisquet-Verrier and Alexinsky 1986; for reviews, see Riccio et al. 1984; Jasnow et al. 2012; Pollack et al. 2018). Consider an early study on memory for the context in which passive avoidance conditioning occurred. Rats were trained in one distinctive context (A) and were later tested in either the same or a neutral context (B). If the retention interval was short $(1 \mathrm{~d})$, rats avoided well only in the original context. That is, they showed what is often called the context change (or shift) effect. However, other groups tested after a long interval ( $2 \mathrm{wk}$ ) showed substantial levels of avoidance in context B as well as A (Zhou and Riccio 1996). Thus, the two contexts had become functionally interchangeable or indistinguishable, and the rats acted as if the neutral context was, in fact, the training context. This finding has been attributed to the "forgetting of stimulus attributes" or "loss of memory precision" for the context (i.e., source) in which the learning took place. In other words, these findings demonstrate that the "what," but not the "where" is well retained at longer delays, just as in human source forgetting.

Such a finding is not an outlier. For example, Biedenkapp and Rudy (2007) gave rats footshock in one context and tested fear either in that context or a different one after one of several delays. Rats showed little fear in the neutral context at the short $(1 \mathrm{~d})$ interval but substantially increased fear after longer retention intervals (7 or $15 \mathrm{~d}$ ). Wiltgen and Silva (2007) used mice in a fear conditioning paradigm and tested after various retention intervals $(1,14,28$, or $36 \mathrm{~d})$. Freezing, the measure of fear, increased in the novel context as a function of the delay interval. Impaired contextual memory for hedonically positive events has also been found. Using a food-preference conditioning paradigm, Winocur et al. 
(2007) found that conditioning was disrupted by a change in context after $1 \mathrm{~d}$. However, the learned response was expressed in the neutral context following an 8 dinterval. Importantly, in all of the cases above the animals did not forget the target response (fear; food preference), but rather their memory impairment was for the situation (source) in which the event occurred. Thus, rodents, like humans, failed to remember the source of their particular experience. Several years ago, Jasnow et al. (2012) noted that this effect was akin to "false memory" in humans, as rats behaved as if a neutral context were now the source of their fear. Consistent with this interpretation, a recent study by Bae et al. (2015) reported a series of findings demonstrating what they described as "false context fear memory in rats." In Experiment 1, the authors found that when rats were preexposed to a distinctive context (A) and were shocked $24 \mathrm{~h}$ later in a different context (B) they froze as much in context $\mathrm{A}$ as they did in context $\mathrm{B}$ during a test the following day. On the other hand, rats that had been preexposed to a control environment (context C) on day one froze significantly more in context B than in (the novel context) A. The authors interpreted their findings as evidence that a false association had been formed between the preexposed context and the aversive shock. In other words, the animals had formed a false memory of having been shocked in A, causing them to show fear in a context that had never been paired with an aversive stimulus. Subsequent experiments ruled out the possibility that greater fear to the preexposed context than to the novel context was the result of "better retrieval of the conditioned B context by the pre-exposed A context" (Experiment 2 ; p. 521) and demonstrated that the preexposed and shocked contexts must be similar for a false memory to occur (Experiment 3).

Although the neurobiological mechanisms underlying this form of memory impairment are neither within our purview nor fully understood at this point, we would note that research has begun to address the issue (e.g., Cullen et al. 2014, 2015; Asok et al. 2019). Interestingly, but at a less molecular level, a number of studies in humans have attempted to determine the specific regions of the brain that are involved in source memory (for review, see Mitchell and Johnson 2009).

\section{Sex differences in source memory: similarities in human and nonhuman animals}

Though there is increased recognition of the importance of sex/ gender differences in behavioral phenomena generally (see Cahill 2006 for extensive review) little attention seems to have been given to the variable of gender where source memory is concerned. In one of the few published studies comparing false memory in men and women, Dewhurst et al. (2012) employed the Deese-Roediger-McDermott (DRM) paradigm, having men and women study lists of related words that were either neutral (e.g., bed, tired, slumber) or negatively valenced (e.g., wicked, devil, sa$\tan )$ and then immediately recall as many words from the list as possible. This paradigm often results in the false recall of "critical lures," words that are thematically related but were not on the studied list. Their results showed that false recall of critical lures was higher in women, but only for negatively valenced lists (there was no gender difference for neutral lists). Although not a direct test of source memory, false memory generation in the DRM paradigm is thought to be due, at least in part, to a failure of source monitoring (mistaking the critical lure as having been in the original list rather than a self-generated associate during either encoding or recall; Gallo and Roediger 2002). A recent study in rats found a similar sex differences with respect to false memory for the source of emotionally related cues. Lynch et al. (2013) gave male and female rats fear conditioning in a distinctive context. When tested at a $1 \mathrm{~d}$ interval, both sexes showed more fear in the training context than the neutral (untrained) context, indicating that the two contexts were perceptually discriminable. To avoid the potential complications of repeated testing (e.g., Asok et al. 2019) separate groups were tested after various retention intervals. At the longer intervals, female rats responded fearfully in a neutral context much as they did in the training context. In contrast, males continued to discriminate between the two contexts at the time points where the female rats were no longer responding differentially. Thus, in both humans and rats, under some conditions females are more likely than males to create false memories resulting (at least in part) from source confusion. This false memory effect seems largely dependent on estrogen, as ovariectomized female rats resulted in contextual memory similar to males (Lynch et al. 2014). Several subsequent analytic experiments elaborated on this outcome by identifying the role of specific estrogen receptors in rats (Lynch et al. 2016). A potentially important implication of this more rapid failure of memory for the source of a painful or traumatic event in females is that it may lead to greater generalization of fear, contributing to the higher incidence of posttraumatic stress disorder (PTSD) and other anxiety disorders in women (e.g., Jasnow et al. 2017).

\section{The misinformation effect and implanted memories}

Moving beyond false memory that occurs due to the forgetting of features of the original episode, a number of important studies have demonstrated that memories can be "implanted" in humans. Beginning in the early 1970s with the seminal work of Elizabeth Loftus and others and continuing today, many laboratories using myriad methodologies have reported that a significant proportion of participants will come to believe that they have a memory for an experience that they have not had (Loftus 1997b, 2004; for review, see Laney and Loftus 2013). For example, in one early study, some adults reported remembering having been lost in a shopping mall when they were 5 yr old-an episode that they had not, in fact, experienced (Loftus and Pickrell 1995). In another study, adults were led to remember spilling a punchbowl at a wedding (Hyman et al. 1995). Lyndsay et al. (2004) took advantage of an irrelevant photograph of an adult's grade school classmates to facilitate implanting the false memory that as a first grader he/she had put "slime" in the teacher's desk. In another study, college students who watched a video were later forced to confabulate an event that did not occur, and for some of them the confabulation later became a false memory (Zaragoza et al. 2001). The literature on implanted false memory has become extensive, and Loftus (2005) and Zaragoza et al. (2019) have provided convenient reviews.

While it is difficult to imagine an adaptation of studies such as those reviewed above for use in animals, a slightly modified version, known as the misinformation paradigm, in which new or misleading information is implanted into an existing memory has been investigated in nonhuman animals. In human studies of the misinformation effect, people are exposed to false information after witnessing a complex event (such as a crime or an automobile accident) but before being asked to recall the details of the event. Numerous studies have shown that this often leads to incorporation of the misinformation into the original memory. A classic study by Loftus (1977) provides a compelling example. In her study, some participants who viewed an automobile accident involving a green car were later asked misleading questions that described the car as blue. When later asked to pick the color of the car from a color wheel, participants who had been exposed to the misleading color information were more likely to pick a color that was "blue-green" than participants who had not been exposed to the misleading color information.

A study by Boller et al. (1990) demonstrated something akin to the misinformation effect in human infants, a population perhaps more like nonhuman animals than human adults in regards 
to memory. In their study, six-month-old infants learned to kick to activate a mobile suspended above their crib in the presence of a distinctive crib liner. If the liner surrounding the crib was changed at testing $1 \mathrm{~d}$ later, responding was impaired (i.e., the context shift effect was obtained). However, if the infants were briefly exposed immediately after training to the liner that would serve as the test context, retention was substantially improved. Presumably, the false memory for context was established because the original memory representation was still in an active state, allowing the original memory to become reencoded by mere exposure to a context not present at learning. As the authors noted, this recoding of contextual information is not unlike the concept of false memory described in the work of Loftus and others.

Can a similar feat be achieved in nonhuman animals? Although research is sparse compared to the human literature, we believe that the answer is, yes. In an intriguing study using a delayed matching to sample task (DMTS), Harper and Garry (2000) demonstrated a type of misinformation effect in pigeons. Their procedure was designed along the general lines of a classic study by McCloskey and Zaragoza (1985). In that research, humans saw a video that was followed by a text containing misleading information about an object in the episode. The critical manipulation was in the type of test given. McCloskey and Zaragoza compared the accuracy of subjects who did or did not ("modified test") have the misleading object among the choices. As those in the modified test condition did not show impaired memory for the item, the authors concluded that the misinformation effect was likely attributable to subjects choosing the misleading stimulus that was typically included as one of the items in the test rather than to the loss of memory for the original information. To explore whether postevent information also biases accuracy in pigeons, Harper and Garry used a two-choice procedure in the DMTS. Following the presentation of the target cue (e.g., red) the pigeons received a postevent stimulus that was consistent with the choice option (red), inconsistent (e.g., green), or neutral (e.g., yellow when the option was red or green). The test choice might then be red vs. green in this set of conditions. The test occurred after one of several delays and the postevent cue was presented either at the start or the end of the delay. The basic outcome was that subjects erroneously chose the incorrect (misleading) stimulus more often in the inconsistent condition than in the other two conditions. However, the effect was only obtained when the manipulation was introduced at the end of the retention interval. The finding was replicated in a second experiment in which three cues were initially presented but only one was later tested for recognition. The intent of this manipulation was to reduce the explicit role of the cue in order to make the procedure more like human studies where a variety of cues co-occur. Thus, as in studies with humans, the presentation of an incorrect posttarget cue shortly before testing biased the choices toward that cue.

A more recent study by Briggs et al. (2007) suggested that a false memory for contextual fear conditioning can be established in rats. That study took advantage of the context shift effect that is typically obtained when testing occurs $1 \mathrm{~d}$ after training in a neutral context. In their study, a group of rats that received a single fear conditioning trial in context A was immediately removed and placed in context B for several minutes. When tested in context $\mathrm{B}$ the following day, the rats showed substantial fear, unlike a control group that had not been exposed to context B. To rule out the possibility that the transfer of fear to the neutral context was simply related to experience with context $\mathrm{B}$, other groups were included that also received exposure to B. However, taking advantage of the evidence that memory representations diminish over time, as has been well established in research on retrograde amnesia, the exposure in those groups occurred after various delays. As would be expected from the amnesia literature, the strength of the "im- planted" fear memory varied as an inverse function of the training to exposure delay interval: At the longest interval, there was no false memory for the neutral context. Using similar procedures, a related experiment showed the same time-dependent transfer of contextual source information for an old memory that was reactivated by exposure to a training cue prior to exposure to the neutral test context (B). Moreover, a subsequent experiment confirmed that the effect was specific to the exposure context, as placing rats in context $\mathrm{C}$ after reactivation did not result in a false memory of fear for the test context (B) (Briggs and Riccio 2008).

In contrast with the strategy of exposing rats to a novel context following conditioning to transfer the memory to untrained cues, a study by Rudy and O'Reilly (2001) provided a different approach to show that learning can be transferred to a context not present at the training. An important aspect of the design took advantage of the "immediate shock effect" demonstrated in a series of studies by Fanselow $(1986,1990)$, which showed that rats receiving a shock immediately after being placed in a context failed to acquire fear to the context, unlike rats given a shock after a brief delay. Presumably, rats were not able to form a representation of the context in the immediate shock condition, precluding conditioning. As part of a series of experiments demonstrating conjunctive memory representations, Rudy and O'Reilly (2001) repeatedly transported rats to a particular context (A) in a distinctive bucket. At the time of conditioning, the rats were again transported in the bucket and placed in a new context (B) where they received an immediate shock and were removed. Consistent with the "immediate shock effect," the rats showed no fear to context (B) in which they had received the immediate shock. However, they did display fear to context $A$, presumably because the transport vehicle had evoked a memory representation of that set of cues. Thus, a false memory was established: fear was not associated with the training cues but with the memory of cues not physically present.

A very different approach to inducing false memory has been provided using sophisticated neuroscientific techniques in the Tonegawa laboratories at MIT. A subset of hippocampal cells of rats that had been labeled during activation in one context (A) were later optogenetically activated while shocks were given in a different context (B). When tested later the rats showed fear in context A even though shocks had never been administered in that context (Ramirez et al. 2013). Thus, a false memory was "implanted" in an otherwise harmless or neutral context.

\section{Implications and applications}

\section{Alleviating impairment}

Taken together, the aforementioned studies suggest that nonhuman animals create false memories that affect their behavior. One might fairly ask, of what consequence is that conclusion? One important feature of animal models of phenomena is that they permit exploration not only of the conditions producing an outcome, such as the misinformation effect or false memory, but also of manipulations that may serve to prevent or alleviate the impairment. Narrowing the range of cues that can elicit an anxiety attack would be of value in many situations. One approach to the problem is suggested by the finding that, in rats, brief reexposure to the original context can reinstate the precision of source memory. For example, rats that failed to distinguish a novel context from the source of fear training after a delay interval showed much less fear in the novel context after a brief exposure to the original context (Zhou and Riccio 1994). However, the recovery of memory precision in that study was relatively brief, lasting for less than an hour. Reinstatement of memory for a source that was more enduring was found in a study by Wiltgen and Silva (2007). Following a 35 d retention interval to allow forgetting of 
the context, mice were given a 1-min reminder of the training context. When tested $24 \mathrm{~h}$ later the mice showed recovery of memory precision relative to those not given the reminder. In an extensive series of experiments with rats, Rosas and Bouton (1997) showed that a context shift shortly after preexposure to a discrete cue reduced the latent inhibition effect but that latent inhibition returned when testing (acquisition) in the neutral context was given $28 \mathrm{~d}$ following preexposure. However, in the latter case, the context shift effect was reinstated by a series of reminder sessions to the original context that ended $24 \mathrm{~h}$ before testing. In a broader sense, reminder treatments might be of value in a clinical therapeutic setting with patients exhibiting generalized fear related to a prior trauma and this could be especially important for female patients, given the findings that they may be more susceptible to creating negatively valenced false memories and may generalize fear memories to a broader array of stimulus conditions than males (Dewhurst et al. 2012; Lynch et al. 2013, respectively).

\section{Relevance to ongoing debates in the false memory literature}

That laboratory animals, whose learning histories and experiences are fully known and controlled, also create false memories may help alleviate the long-standing concern expressed by some critics that human false memory studies may simply have been extracting true autobiographical memories rather than implanting false ones (for review, see Loftus 2004). Although false memory researchers went to great lengths to ensure that the memories they attempted to implant were highly unlikely to have been experienced by their participants (see Braun et al. 2002) lingering doubts remained, and that possibility could never be entirely ruled out. An advantage of false memories in lower animals is that they cannot be explained by such a mechanism.

Another advantage of using animal models to study false memory relates to the empirical testing of the plausibility of implanting false trauma memories, which is complicated by ethical considerations in research with human participants. Based on the copious literature demonstrating the relative ease of implanting false memories in human research participants, Loftus and others have expressed concern that psychotherapeutic techniques that ask patients to "guess," "tell a story," or "imagine" sexual abuse or other traumatic experiences to help them "regain access" to repressed memories might contribute to the creation of false trauma memories (for review, see Loftus 1993). Although Loftus has provided compelling anecdotal evidence that false abuse memories can be implanted due to suggestions by police or therapists (for a particularly fascinating example, see Loftus 1993, in which she recounts the story of a man who confessed to a crime that was intentionally implanted by a psychologist working for the prosecution), and there are experimental studies in humans showing that memory for stressful childhood events can be implanted in college-aged adults (e.g., Porter et al. 1999), experimental work in animals could further elucidate this likelihood and would have the advantage of not being complicated by alternative explanations, such as demand characteristics or the possibility that the participant had actually experienced the "implanted" trauma.

\section{Conclusion}

In this review, we have suggested that at least some of the phenomena associated with false memories in humans can be produced in rodents and other lower animals. We propose that animal models can provide a means to investigate further some of the intriguing characteristics of "false memory" and help elucidate those characteristics that differentiate them from real memories (perhaps at the molecular, as well as the behavioral level). Moreover, the use of an- imal models may help address some of the criticisms of earlier human experimental work on false memories and permit the exploration of interventions aimed at reducing false memories, which may, in part contribute to some types of pathology.

\section{Acknowledgments}

P.M.M. wishes to thank Kenyon College for supporting this work during her sabbatical. D.C.R. wishes to thank the Department of Psychological Sciences at Kent State University for its continued encouragement during the writing of this paper.

\section{References}

Asok A, Hijazi J, Harvey LR, Kosmidis S, Kandel ER, Rayman JB. 2019. Sex differences in remote contextual fear generalization in mice. Front Behav Neurosci 13: 1-13. doi:10.3389/fnbeh.2019.00056

Babb SJ, Crystal JD. 2005. Discrimination of what, when, and where: implications for episodic-like memory in rats. Learn Motiv 36: 177-189. doi:10.1016/j.lmot.2005.02.009

Bae SE, Holmes NM, Westbrook FR. 2015. False context fear memory in rats. Learn Mem 22: 519-525. doi:10.1101/lm.039065.115

Basile BM. 2015. Rats remind us what actually counts in episodic memory research. Front Psychol 6: 1-2. doi:10.3389/fpsyg.2015.00075

Biedenkapp JC, Rudy JW. 2007. Context preexposure prevents forgetting of a contextual fear memory: implication for regional changes in brain activation patterns associated with recent and remote memory tests. Learn Mem 14: 200-203. doi:10.1101/lm.499407

Boller K, Rovee-Collier C, Borovsky D, O'Connor J, Shyi G. 1990. Developmental changes in the time-dependent nature of memory retrieval. Dev Psychol 26: 770-779. http://dx.doi.org/10.1037/00121649.26.5.770

Braun KA, Ellis R, Loftus EF. 2002. Make my memory: how advertising can change our memories of the past. Psychol Mark 19: 1-23. doi:10.1002/ mar.1000

Briggs JF, Riccio DC. 2008. Transfer of old 'reactivated' memory retrieval cues in rats. Learn Motiv 39: 13-23. doi:10.1016/j.lmot.2007.04.001

Briggs JF, Fitz KI, Riccio DC. 2007. Transfer of memory retrieval cues in rats. Psychon Bull Rev 14: 495-499. doi:10.3758/BF03194096

Brown E, Deffenbacher K, Sturgill W. 1977. Memory for faces and the circumstances of encounter. J Appl Psychol 62: 311-318. doi:10.1037/ 0021-9010.62.3.311

Cahill L. 2006. Why sex matters for neuroscience. Nat Rev Neurosci 7: 477484. doi:10.1038/nrn1909

Campbell BA, Campbell EH. 1962. Retention and extinction of learned fear in infant and adult rats. J Comp Physiol Psychol 55: 1-8. doi:10.1037/ h0049182

Clayton NS, Dickinson A. 1999. Episodic-like memory during cache recovery by scrub jays. Nature 395: $272-274$. doi:10.1038/26216

Cullen PC, Dulka BN, Ortiz S, Riccio DC, Jasnow AM. 2014. GABA-mediated presynaptic inhibition is required for precision of long-term memory. Learn Mem 21: 180-184. doi:10.1101/lm.032961.113

Cullen PC, Gilman TL, Winiecki P, Riccio DC, Jasnow AM. 2015. Activity of the anterior cingulate cortex and ventral hippocampus underlie increases in contextual fear generalization. Neurobiol Learn Mem 124: 19-27. doi:10.1016/j.nlm.2015.07.001

Dere E, Huston JP, Kart-Teke E, Silva MA. 2006. The case for episodic memory in animals. Neurosci Biobehav Rev 30: 1206-1224. doi:10.1016/j .neubiorev.2006.09.005

Dewhurst SA, Anderson RJ, Knott LM. 2012. A gender difference in the false recall of negative words: women DRM more than men. Cogn Emot 26: 65-74. doi:10.1080/02699931.2011.553037

Fanselow MS. 1986. Associative vs topographical accounts of the immediate shock-freezing deficit in rats: implication for the response selection rules governing species-specific defensive reactions. Learn Motiv 17: 16-39. doi:10.1016/0023-9690(86)90018-4

Fanselow MS. 1990. Factors governing one-trial contextual conditioning. Anim Learn Behav 18: 264-270. doi:10.3758/BF03205285

Fortin NJ, Wright SP, Eichenbaum H. 2004. Recollection-like memory retrieval in rats is dependent on the hippocampus. Nature 431: 188-191. doi:10.1038/nature02853

Gallo DA, Roediger HL III. 2002. Variability among word lists in eliciting memory illusions: Evidence for associative activation and monitoring. $J$ Mem Lang 47: 469-497. doi:10.1016/S0749-596X(02)00013-X

Gisquet-Verrier P, Alexinsky T. 1986. Does contextual change determine long-term forgetting? Anim Learn Behav 14: 349-358. doi:10.3758/ BF03200078

Guttman N, Kalish HI. 1956. Discriminability and stimulus generalization.J Exp Psychol 51: 79-88. doi:10.1037/h0046219 
Harper DN, Garry M. 2000. Postevent cues bias recognition performance in pigeons. Anim Learn Behav 28: 59-67. doi:10.3758/BF03199772

Hyman IE, Husband TH, Billings FJ. 1995. False memories of childhood experiences. Appl Cogn Psychol 9: 181-197. doi:10.1002/acp .2350090302

Jasnow AM, Cullen PK, Riccio DC. 2012. Remembering another aspect of forgetting. Front Psychol 3: 1-8. doi:10.3389/fpsyg.2012.00175

Jasnow AM, Lynch JF, Gilman TL, Riccio DC. 2017. Perspectives on fear generalization and its implications for emotional disorders. J Neurosci Res 95: $821-835$. doi: $10.1002 / j n r .23837$

Johnson MK, Hashtroudi S, Lindsay DS. 1993. Source monitoring. Psychol Bull 114: 3-28. doi:10.1037/0033-2909.114.1.3

Laney C, Loftus EF. 2013. Recent advances in false memory research. $S$ Afr J Psychol 43: 137-146. doi:10.1177/0081246313484236

Loftus EF. 1977. Shifting human color memory. Mem Cogn 5: 696-699. doi:10.3758/BF03197418

Loftus EF. 1993. The reality of repressed memories. Am Psychol 48: 518-537. doi:10.1037/0003-066X.48.5.518

Loftus EF. 1997a. Creating false memories. Sci Am 277: 70-75. doi:10.1038/ scientificamerican0997-70

Loftus EF. 1997b. Memory for a past that never was. Curr Dir Psychol Sci 6: 60-65. doi:10.1111/1467-8721.ep11512654

Loftus EF. 2004. Memories of things unseen. Curr Dir Psychol Sci 13: 145147. doi:10.1111/j.0963-7214.2004.00294.x

Loftus EF. 2005. Planting misinformation in the human mind: a 30-year investigation of the malleability of memory. Learn Mem 12: 361-366. doi:10.1101/lm.94705

Loftus EF, Pickrell JE. 1995. The formation of false memories. Psychiatr Ann 25: 720-725. doi:10.3928/0048-5713-19951201-07

Lynch J, Cullen PK, Jasnow AM, Riccio DC. 2013. Sex differences in the generalization of fear as a function of retention intervals. Learn Mem 20: 628-632. doi:10.1101/lm.032011.113

Lynch J III, Dejanovic D, Winiecki P, Mulvany J, Ortiz S, Riccio DC, Jasnow AM. 2014. Activation of ER $\beta$ modulates fear generalization through an effect on memory retrieval. Horm Behav 66: 421-429. doi:10 .1016/j.yhbeh.2014.06.017

Lynch JF, Winiecki P, Vanderhoof D, Riccio DC, Jasnow AM. 2016. Hippocampal cytosolic estrogen receptors regulate fear generalization in females. Neurobiol Learn Mem 130: 83-92. doi:10.1016/j.nlm.2016.01 .010

Lyndsay DS, Hagen L, Read JD, Wade KA, Garry M. 2004. True photographs and false memories. Psychol Sci 15: 149-154. doi:10.1111/j.0956-7976 .2004.01503002.x

McAllister WR, McAllister DE. 1963. Increase over time in the stimulus generalization of acquired fear. J Exp Psychol 65: 576-582. doi:10.1037/ h0046583

McCloskey M, Zaragoza M. 1985. Misleading postevent information and memory for events: arguments and evidence against memory impairment hypotheses. J Exp Psychol Gen 114: 1-16.

Mitchell KJ, Johnson MK. 2009. Source monitoring 15 years later: what have we learned from fMRI about the neural mechanisms of source memory? Psychol Bull 135: 638-677. doi:10.1037/a0015849

Perkins CC, Weyant RG. 1958. The interval between training and test trials as a determiner of the slope of generalization gradients. J Comp Physiol Psychol 51: 596-600. doi:10.1037/h0042550

Pollack GA, Bezek JL, Lee SH, Scarlata MJ, Weingast LT, Bergstrom HC. 2018. Cued fear memory generalization increases over time. Learn Mem 25: 298-308. doi:10.1101/lm.047555.118
Porter S, Yuille JC, Lehman DR. 1999. The nature of real, implanted, and fabricated memories for emotional childhood events: implications for the recovered memory debate. Law Hum Behav 23: 517-537. doi:10 1023/A:1022344128649

Ramirez S, Liu X, Lin PA, Suh J, Pignatelli M, Redondo RL, Ryan TJ, Tonegawa S. 2013. Creating a false memory in the hippocampus. Science 341: 387-391. doi:10.1126/science.1239073

Riccio DC, Richardson R, Ebner DL. 1984. Memory retrieval deficits based upon altered contextual cues: a paradox. Psychol Bull 96: 152-165. doi:10.1037/0033-2909.96.1.152

Rosas JM, Bouton ME. 1997. Additivity of the effects of retention interval and context change on latent inhibition: toward resolution of the context forgetting paradox. J Exp Psychol Anim Behav Process 23: 283294. doi:10.1037/0097-7403.23.3.283

Rudy JW, O'Reilly RC. 2001. Conjunctive representations, the hippocampus, and contextual fear conditioning. Cogn Affect Behav Neurosci 1: 66-82. doi:10.3758/CABN.1.1.66

Schacter DL, Harbluk JL, McLachlan DR. 1984. Retrieval without recollection: an experimental analysis of source amnesia. J Verbal Learn Verbal Behav 23: 593-611. doi:10.1016/S0022-5371(84)90373-6

Thomas DR, Burr DES. 1969. Stimulus generalization as a function of the delay between training and testing: a reevaluation. J Exp Anal Behav 12: 105-109. doi:10.1901/jeab.1969.12-105

Thomas DR, Lopez LJ. 1962. The effects of delayed testing on generalization slope. J Comp Physiol Psychol 55: 541-544. doi:10.1037/h0046103

Wade KA, Sharman SJ, Garry M, Memon A, Mazzoni G, Merckelbach H, Loftus EF. 2007. False claims about false memory research. Conscious Cogn 16: 18-28. doi:10.1016/j.concog.2006.07.001

Watson JB, Rayner R. 1920. Conditioned emotional reaction. J Exp Psychol 3: 1-14. doi:10.1037/h0069608

Wiltgen BJ, Silva AJ. 2007. Memory for context becomes less specific with time. Learn Mem 14: 313-317. doi:10.1101/lm.430907

Winocur G, Moscovitch M, Sekeres M. 2007. Memory consolidation or transformation: context manipulation and hippocampal representations of memory. Nat Neurosci 10: 555-557. doi:10.1038/ nn1880

Zaragoza MS, Payment KE, Ackil JK, Drivdahl SB, Beck M. 2001. Interviewing witnesses: forced confabulation and confirmatory feedback increase false memories. Psychol Sci 12: 473-477. doi:10.1111/1467-9280.00388

Zaragoza MS, Belli R, Payment KE. 2007. Misinformation effects and the suggestibility of eyewitness memory. In Do justice and let the sky fall: Elizabeth Loftus and her contributions to science, law, and academic freedom (ed. Garry M, Hayne H), pp. 35-63. Lawrence Erlbaum Associates, Mahwah, NJ.

Zaragoza M, Hyman I, Chrobak Q. 2019. False memories. In: Improving the criminal justice system: perspectives from psychological science (ed. Brewer $\mathrm{N}$ Bradfield-Douglass A). Guilford Press, New York.

Zentall TR, Clement TS, Bhatt RS, Allen J. 2001. Episodic-like memory in pigeons. Psychon Bull Rev 8: 685-690. doi:10.3758/BF03196204

Zhou Y, Riccio DC. 1994. Pretest cuing can alleviate the forgetting of contextual stimulus attributes. Learn Motiv 25: 233-244. doi:10.1006/ Imot.1994.1013

Zhou Y, Riccio DC. 1996. Manipulation of components of context: the context shift effect and forgetting of stimulus attributes. Learn Motiv 27: 400-407. doi:10.1006/lmot.1996.0023

Received June 3, 2019; accepted in revised form July 20, 2019. 


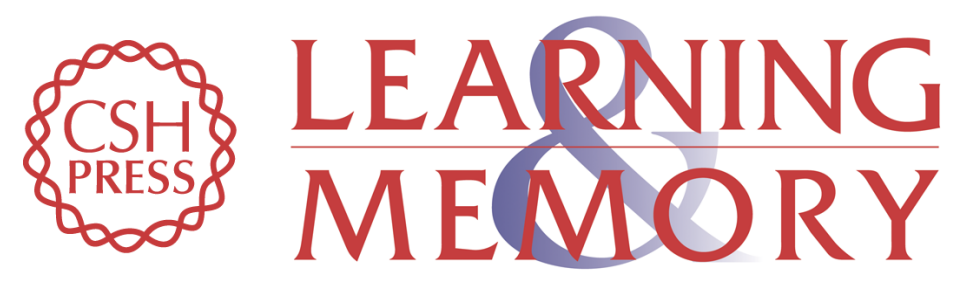

\section{False memory in nonhuman animals}

Paula M. Millin and David C. Riccio

Learn. Mem. 2019, 26:

Access the most recent version at doi:10.1101/lm.050054.119

References This article cites 61 articles, 8 of which can be accessed free at: http://learnmem.cshlp.org/content/26/10/381.full.html\#ref-list-1

Creative This article is distributed exclusively by Cold Spring Harbor Laboratory Press for the Commons first 12 months after the full-issue publication date (see

License http://learnmem.cshlp.org/site/misc/terms.xhtml). After 12 months, it is available under a Creative Commons License (Attribution-NonCommercial 4.0 International), as described at http://creativecommons.org/licenses/by-nc/4.0/.

Email Alerting Receive free email alerts when new articles cite this article - sign up in the box at the Service top right corner of the article or click here. 